\title{
Imatinib induced severe skin reactions and neutropenia in a patient with gastrointestinal stromal tumor
}

\author{
Jun-Eul Hwang ${ }^{1}$, Ju-Young Yoon', Woo-Kyun Bae', Hyun-Jeong Shim¹, Sang-Hee Cho', Ik-Joo Chung ${ }^{1,2^{*}}$
}

\begin{abstract}
Background: Imatinib mesylate has been used for the treatment of unresectable or metastatic gastrointestinal stromal tumors (GIST). The current recommended dose of imatinib is $400 \mathrm{mg} /$ day that is increased to $800 \mathrm{mg} /$ day in cases with disease progression. However, imatinib can be associated with diverse adverse events, which has limited its use. We report a case of severe adverse skin reactions with neutropenic fever during imatinib treatment in a patient with GIST.

Case presentation: A 71-year-old man was admitted with a one month history of epigastric pain and a palpable mass in the right upper quadrant. An abdominal CT scan revealed a $20 \times 19 \mathrm{~cm}$ intraabdominal mass with tumor invasion into the peritoneum. Needle biopsy was performed and the results showed spindle shaped tumor cells that were positive for c-KIT. The patient was diagnosed with unresectable GIST. Imatinib $400 \mathrm{mg} /$ day was started. The patient tolerated the first eight weeks of treatment. However, about three months later, the patient developed a grade 4 febrile neutropenia and a grade 3 exfoliative skin rash. The patient recovered from this serious adverse events after discontinuation of imatinib with supportive care. However, the skin lesions recurred whenever the patient received imatinib over $100 \mathrm{mg} /$ day. Therefore, imatinib $100 \mathrm{mg} /$ day was maintained. Despite the low dose imatinib, follow up CT showed a marked partial response without grade 3 or 4 toxicities.

Conclusion: The recommended dose of imatinib for the treatment of GIST is $400 \mathrm{mg} /$ day but patients at risk for adverse drug reaction may benefit from lower doses. Individualized treatment is needed for such patients, and we may also try sunitinib as a alternative drug.
\end{abstract}

\section{Background}

Imatinib mesylate is a selective tyrosine kinase inhibitor. It has become the gold standard treatment for unresectable or metastatic gastrointestinal stromal tumors (GIST). It has inhibitory activity against, BCR-ABL, c-KIT, and PDGFR [1,2]. The most common adverse events associated with imatinib include edema that is most frequently periorbital, nausea, diarrhea, muscle cramps, fatigue, skin rash, headache, and abdominal pain. Imatinib induced grade 3-4 neutropenia and skin rash may occur in as many as $7.1 \%$ and $3.8 \%$ of GIST patients, respectively $[3,4]$. The toxicities are generally mild or moderate and of grade 1 or 2 severity (NCI-

\footnotetext{
* Correspondence: ijchung@chonnam.ac.kr

'Department of Hematology-Oncology, Chonnam National University

Medical School, Gwangju 501-757, South Korea

Full list of author information is available at the end of the article
}

CTC). Rarely, serious gastrointestinal or intraabdominal hemorrhage can occur in patients with large, bulky tumors [2,3]. Most cutaneous reactions are mild, however, severe reactions such as exfoliative dermatitis, toxic epidermal necrolysis and Stevens Johnson syndrome can also occur [5]. Sunitinib has demonstrated efficacy in treating patients with GIST who have experienced disease progression on or intolerance to imatinib [6]. However, due to the effectiveness of imatinib, imatinib may need to be used again in some patients despite a history of severe reactions. We report a case of severe adverse skin reactions with neutropenic fever during imatinib treatment.

\section{Case presentation}

A 71-year-old man was admitted with a one month history of epigastric pain and a palpable mass in the right 


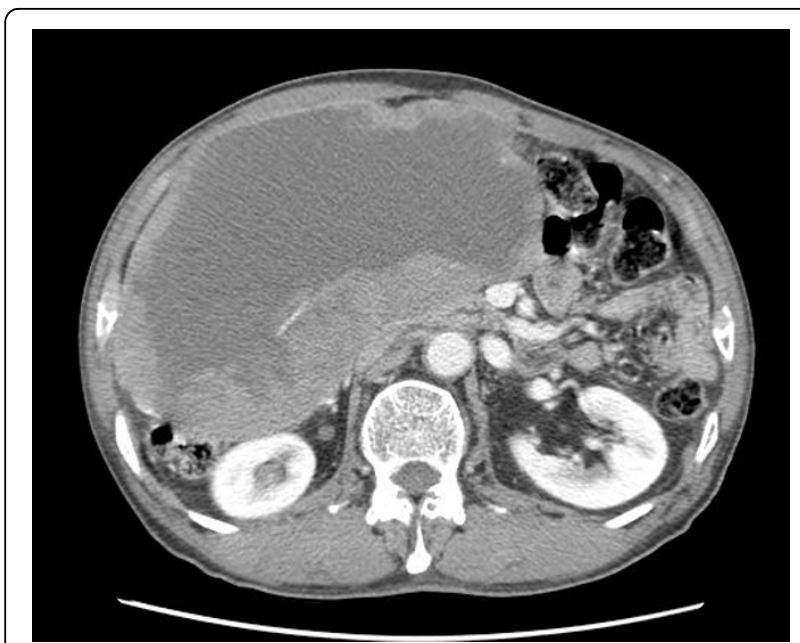

Figure 1 Initial CT scan showed a $20 \times 19 \mathrm{~cm}$ intraabdominal mass with central necrosis in the infra-hepatic space and tumor invasion into the peritoneum.

upper quadrant. The patient had no significant past medical history. A CT scan of the abdomen showed a $20 \times 19 \mathrm{~cm}$ intraabdominal mass with central necrosis in the infra-hepatic space and tumor invasion into the peritoneum (Figure 1). For a definitive diagnosis, ultrasound guided needle biopsy was performed. The results showed spindle shaped tumor cells that were strongly positive for c-KIT by CD 117 immunohistochemical staining; other immunohistochemical staining was negative including actin, desmin, S-100 and CD 34 (Figures 2 ). The mitotic figures were $>5 / 50$ high power field. Because the mass invaded the peritoneum, the patient was diagnosed with unresectable GIST. Given this

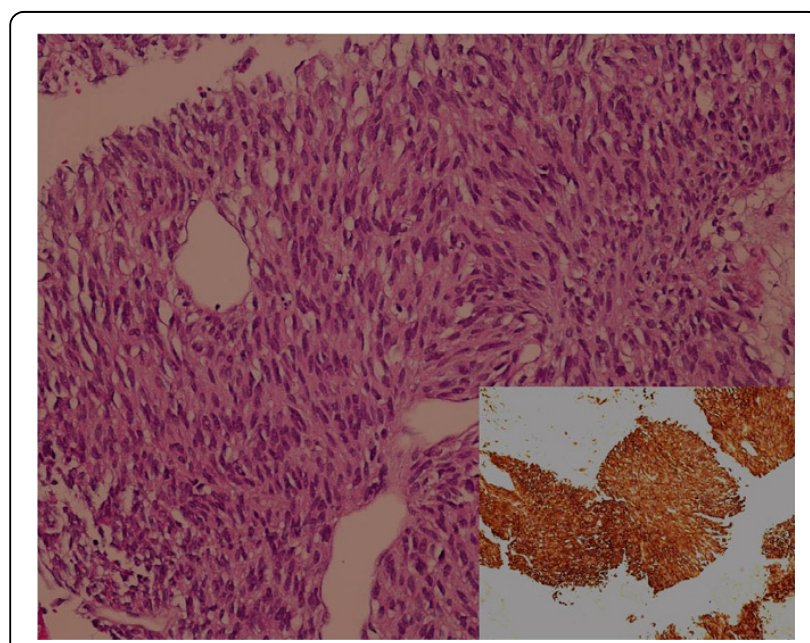

Figure 2 Microscopic finding of the intraabdominal GIST demonstrating spindle cells (H\&E; magnification, $\times 20$ ). The tumor cells were strongly positive for c-KIT (small picture, magnification, $\times 10$ ). diagnosis, treatment with imatinib at a dose of $400 \mathrm{mg}$ daily was started. The patient tolerated the first eight weeks of treatment; the only toxicities were mild periorbital edema and pruritus. However, about three months after beginning treatment, the patient developed mild diarrhea, a grade 4 febrile neutropenia, and a grade 3 generalized erythematous maculopapular rash covered by whitish dry scales affecting the face, trunk and upper limbs (Figures 3 ). The patient did not developed any other lymphadenopathy and there were no oral mucosal lesions. The patient was admitted to the hospital and reported general weakness, loss of appetite, and visual problems including conjunctival suffusion and itching of both eyes. The periorbital edema was so severe that he could not open his eyes. The vital signs showed a high fever (temperature of $38.6^{\circ} \mathrm{C}$, blood pressure $120 / 70$ $\mathrm{mmHg}$, heart rate $72 /$ minute, and respiratory rate 18 / minute). Laboratory examination revealed neutropenia, eosinophilila and a mild anemia, that is, white blood cell count $2.5 \times 10^{9} / \mathrm{L}$ (reference value $4-10.8 \times 10^{9} / \mathrm{L}$ ), absolute neutrophil count $0.15 \times 10^{9} / \mathrm{L}$ (reference value $>1.5 \times 10^{9} / \mathrm{L}$ ), eosinophil count $1.25 \times 10^{9} / \mathrm{L}$ (percent eosinophil 50\%) (reference value percent eosinophil 0-7\%), hemoglobin $10.2 \mathrm{~g} / \mathrm{dl}$ (12-18 g/dl), platelet count

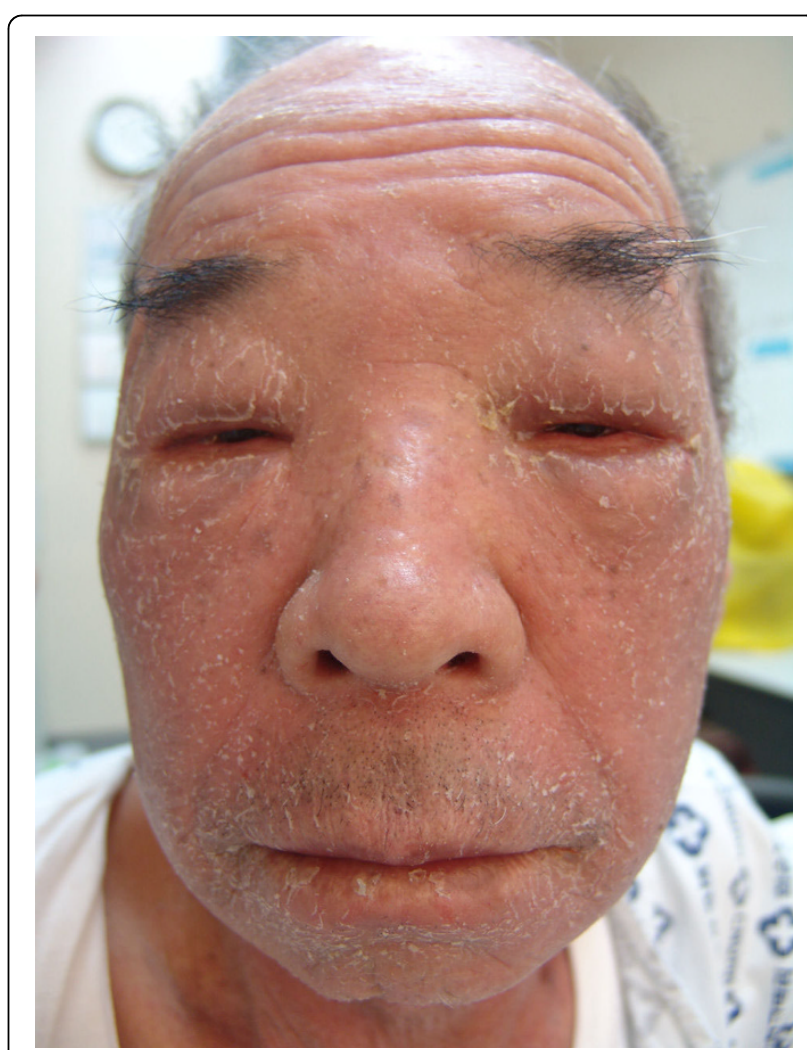

Figure 3 The patient had marked periorbital edema, and an erythematous maculopapular rash covered by whitish dry scales affecting the face. 
$218 \times 10^{9} / \mathrm{L}\left(130-450 \times 10^{9} / \mathrm{L}\right)$. Other blood chemistries revealed alkaline phosphatase 386 IU/L (39-117 IU/L), aspartate aminotransferase $66 \mathrm{IU} / \mathrm{L}$ (7-38 IU/L), alanine aminotransferase $161 \mathrm{IU} / \mathrm{L}$ (4-43 IU/L), lactate dehydrogenase $498 \mathrm{IU} / \mathrm{L}(218-472 \mathrm{IU} / \mathrm{L})$, total bilirubin $3.9 \mathrm{mg} /$ $\mathrm{dL}(0.35-1.3 \mathrm{mg} / \mathrm{dL})$, blood urea nitrogen $29 \mathrm{mg} / \mathrm{dL}$ (8-23 mg/dL), creatinine $1.4 \mathrm{mg} / \mathrm{dL}(0.5-1.3 \mathrm{mg} / \mathrm{dL})$. Mild hepatic and renal dysfunction was suspected. The patient was taking no other medication except for imatinib. Therefore, administration of imatinib was promptly discontinued, and a dermatological consultation was obtained.

The cutaneous findings were compatible with the diagnosis of an exfoliative dermatitis due to imatinib. The patient was managed with hydration and parenteral injections of a third generation cephalosporin as well as granulocyte colony stimulating factor. For the skin lesion management, systemic steroids (oral prednisone $30 \mathrm{mg} /$ day) with topical steroid and emollient cream were provided. The patient recovered from the febrile neutropenia, and the eosinophil count normalized subsequently. The results of blood culture was negative and there were no infection foci. The skin lesions gradually improved with a reduction of the extension and severity of the erythema and scales. Further dermatological treatment was continued and one month later the rashes completely resolved with hyperpigmented areas remaining.

After the skin lesions improved, that is, one month later after stopping the imatinib, the drug was started at a dose of $100 \mathrm{mg}$ every other day for 1 week without any complications. The dose was increased to $100 \mathrm{mg}$ daily and the patient tolerated this dose. Subsequently the imatinib was increased to $200 \mathrm{mg}$ daily, and then the periorbital edema and exfoliative skin lesions recurred on the forth day after the dose increase. Laboratory examination also showed increased liver enzyme, AST 89 IU/L, ALT $133 \mathrm{IU} / \mathrm{L}$, and LDH $941 \mathrm{IU} / \mathrm{L}$. We tried several times to increase the dose of imatinib. However, severe exfoliative dermatitis, periorbital edema, and elevation of liver enzymes developed each time. The combined steroid therapy was somewhat effective, but the exfoliative skin lesions progressed. After complete recovery, the imatinib was started again at a dose of $100 \mathrm{mg}$ daily and this was maintained. Serial CT was performed to evaluate the tumor response. The first follow up CT was performed three months after starting the imatinib medication. The CT showed a partial response according to RECIST criteria, that is, the tumor decreased from $20 \times 19 \mathrm{~cm}$ to $14 \times 8 \mathrm{~cm}$. At the second follow up CT after the patient received imatinib for about 3 weeks, during the prior 3 months due to severe hypersensivity reaction the CT showed a decrease in the tumor. Therefore, the patient has been maintained on imatinib $100 \mathrm{mg}$ daily with CT follow up every 3-months. Despite

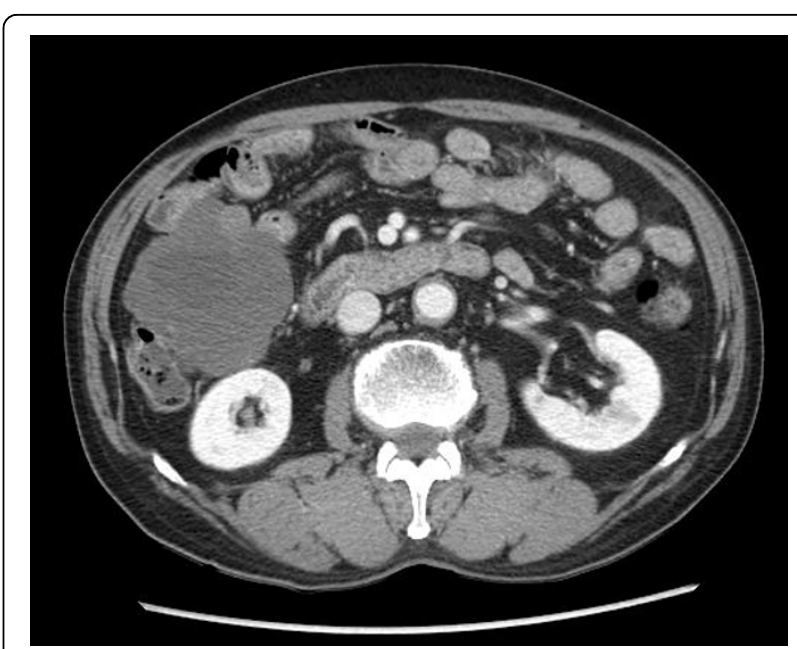

Figure 4 Last follow up CT scan revealed a partial response The tumor decreased to $8 \times 8 \mathrm{~cm}$.

the low dose imatinib, the last follow up CT revealed a prolonged partial response, and the tumor decreased to $8 \times 8 \mathrm{~cm}$ (Figure 4).

\section{Conclusion}

Gastrointestinal stromal tumors (GIST) are a subtype of sarcomas that have a unique natural history. Imatinib mesylate, a selective tyrosine kinase inhibitor, has become the gold standard for the treatment of unresectable or metastatic GIST [1].

Skin rashes are a well recognized side effect of imatinib treatment. In most cases, the lesions are mild, self limiting, and easily managed with anti-histamines or topical steroids, whereas a short course of oral steroids can be used to treat more severe cases [7]. Grade 3 or 4 skin rashes may occur in $3.8 \%$ of patients. In some patients, severe rashes can develop with desquamative components, including a report of Steven-Johnson syndrome [8-10]. In such cases, immediate discontinuation of therapy and systemic steroids are indicated. Severe skin lesions that were resistant to supportive measures have been the most frequent cause for permanent discontinuation of imatinib therapy. However, the frequency of this event is small ( $<1 \%$ of all patients) [7].

Standard management of drug induced skin rashes usually includes discontinuation of the suspected drug and avoidance of further exposure to this drug in the future. However, due to the effectiveness of imatinib, most oncologists try to maintain or reinitiate treatment with imatinib. To overcome severe skin reactions, several methods such as temporary discontinuation of imatinib treatment, once weekly dosing, a lower daily dose with or without a short course of an oral corticosteroid, and gradual dose escalation, have been reported $[11-13,9,14]$. 
In this case, febrile neutropenia resolved as soon as treatment was initiated and the skin rashes resolved gradually over one month. We started the imatinib again, but we could not increase the dose above $100 \mathrm{mg} /$ day due to recurrence of the lesions. However, even with the low dose of imatinib, $100 \mathrm{mg} /$ day, follow up CT demonstrated a decreased tumor mass. We could also try sunitinib which had demonstrated efficacy in treating patients with GIST who have experienced disease progression on or intolerance to imatinib [6]. However, the patient had good tumor response to imatinib, therefore we tried to maintain the imatinib.

Several studies have reported a dose related skin toxicity of imatinib, indicating a pharmacological effect of imatinib. This case can also mainly be related to the pharmacological effect of imatinib, but the delayed type hypersensitivity might be involved in some aspects like other skin rashes considering eosinophilia and pruritus [15-17]. The cause of the skin rashes is unclear. However, the platelet derived growth factor receptor is found abundantly in keratinocytes, and its inhibition by imatinib may play a role in the occurrence of this reaction [14]. Other investigators have proposed that certain skin reactions may result from an inhibition of KIT, found in basal cells $[7,14,18]$. However, it is unclear why these severe skin rashes develop in only a minority of patients.

Recently, Demetri et al. suggested that imatinib trough levels at steady state were associated with a clinical benefit [19]. According to this report, patients with an imatinib trough concentration, below $1,100 \mathrm{ng} / \mathrm{ml}$, showed a shorter time to progression (11.3 months) and lower rate of clinical benefit. In our case, the trough concentration at steady state was $331 \mathrm{ng} / \mathrm{ml}$. It remains to be seen whether the tumor will progress earlier or maintain a partial response. However, to date, the patient has showed a good tumor response over 14 months. The current recommended daily dose of imatinib is $400 \mathrm{mg}$, however, patients at risk for adverse drug reactions may benefit from lower doses. Individualized treatment is needed for such patients, and we may also try sunitinib as a alternative drug.

In conclusion, we describe a patient with an intraabdominal GIST that had a good tumor response, although we could not increase the dose of imatinib above $100 \mathrm{mg} /$ day due to severe adverse skin reactions.

\section{Consent}

Written informed consent was obtained from the patient for publication of this case report and any accompanying clinical images, including the image of the face.

\section{Author details}

${ }^{1}$ Department of Hematology-Oncology, Chonnam National University Medical School, Gwangju 501-757, South Korea. ${ }^{2}$ The Brain Korea 21 Project,
Center for Biomedical Human Resources, Jeonnam Regional Cancer Center, Chonnam National University Hwasun Hospital, Hwasun, Jeollanam-do, South Korea.

\section{Authors' contributions}

Jun-Eul Hwang is main author. YJY, WKB, HJS, SHC, IJC made substantial contributions to the conception and interpretation of clinical data and case related studies, and clinical decisions. All authors read and approved the final manuscript.

\section{Competing interests}

The authors declare that they have no competing interests.

Received: 8 December 2009 Accepted: 18 August 2010 Published: 18 August 2010

\section{References}

1. Rubin BP, Heinrich MC, Corless CL: Gastrointestinal stromal tumour. Lancet 2007, 369:1731-1741.

2. Zalcberg JR, Verweij J, Casali PG, Le Cesne A, Reichardt P, Blay JY, Schlemmer M, Van Glabbeke M, Brown M, Judson IR: Outcome of patients with advanced gastro-intestinal stromal tumours crossing over to a daily imatinib dose of $800 \mathrm{mg}$ after progression on $400 \mathrm{mg}$. Eur J Cancer 2005, 41:1751-1757.

3. Demetri GD, von Mehren M, Blanke $C D$, Van den Abbeele AD, Eisenberg $B$, Roberts PJ, Heinrich MC, Tuveson DA, Singer $S$, Janicek $M$, Fletcher JA, Silverman SG, Silberman SL, Capdeville R, Kiese B, Peng B, Dimitrijevic S, Druker BJ, Corless C, Fletcher CD, Joensuu H: Efficacy and safety of imatinib mesylate in advanced gastrointestinal stromal tumors. $N$ Engl J Med 2002, 347:472-480.

4. Van Glabbeke M, Verweij J, Casali PG, Simes J, Le Cesne A, Reichardt P, Issels R, Judson IR, van Oosterom AT, Blay JY: Predicting toxicities for patients with advanced gastrointestinal stromal tumours treated with imatinib: a study of the European Organisation for Research and Treatment of Cancer, the Italian Sarcoma Group, and the Australasian Gastro-Intestinal Trials Group (EORTC-ISG-AGITG). Eur J Cancer 2006, 42:2277-2285.

5. Scheinfeld N: Imatinib mesylate and dermatology part 2: a review of the cutaneous side effects of imatinib mesylate. J Drugs Dermatol 2006, 5:228-231.

6. Wolter P, Schoffski P: Targeted therapies in the treatment of GIST:Adverse events and maximising the bnefits of sunitinib through proactive therapy management. Acta Oncol 2010, 49:13-23.

7. Deininger MW, O'Brien SG, Ford JM, Druker BJ: Practical management of patients with chronic myeloid leukemia receiving imatinib. J Clin Oncol 2003, 21:1637-1647.

8. Ferraresi V, Catricala C, Ciccarese M, Ferrari A, Zeuli M, Cognetti F: Severe skin reaction in a patient with gastrointestinal stromal tumor treated with imatinib mesylate. Anticancer Res 2006, 26:4771-4774.

9. Hsiao LT, Chung HM, Lin JT, Chiou TJ, Liu JH, Fan FS, Wang WS, Yen CC, Chen PM: Stevens-Johnson syndrome after treatment with STI571: a case report. Br J Haematol 2002, 117:620-622.

10. Scott LC, White JD, Reid R, Cowie F: Management of Skin Toxicity Related to the Use of Imatinib Mesylate (STI571, Glivectrade mark) for Advanced Stage Gastrointestinal Stromal Tumours. Sarcoma 2005, 9:157-160.

11. Rule SA, O'Brien SG, Crossman LC: Managing cutaneous reactions to imatinib therapy. Blood 2002, 100:3434-3435.

12. Milojkovic D, Short K, Salisbury JR, Creamer D, du Vivier AW, Mufti GJ: Doselimiting dermatological toxicity secondary to imatinib mesylate (STI571) in chronic myeloid leukaemia. Leukemia 2003, 17:1414-1416.

13. Park MA, Volcheck GW, Guarderas JC: Successful progressive challenge after a cutaneous reaction to imatinib mesylate (Gleevec): a case report and review of the literature. Allergy Asthma Proc 2004, 25:345-347.

14. Tanvetyanon T, Nand S: Overcoming recurrent cutaneous reactions from imatinib using once-weekly dosing. Ann Pharmacother 2003, 37:1818-1820.

15. Valeyrie L, Bastuji-Garin S, Revuz J, Bachot N, Wechsler J, Berthaud P Tulliez M, Giraudier S: Adverse cutaneous reactions to imatinib (STI571) in Philadelphia chromosome-positive leukemias: a prospective study of 54 patients. J Am Acad Dermatol 2003, 48:201-206.

16. Brouard M, Saurat JH: Cutaneous reactions to STI571. N Engl J Med 2001, 345:618-619. 
17. Joensuu H, Roberts PJ, Sarlomo-Rikala M, Andersson LC, Tervahartiala P, Tuveson D, Silberman S, Capdeville R, Dimitrijevic S, Druker B, Demetri GD: Effect of the tyrosine kinase inhibitor STI571 in a patient with a metastatic gastrointestinal stromal tumor. N Engl J Med 2001, 344:1052-1056.

18. Lammie A, Drobnjak M, Gerald W, Saad A, Cote R, Cordon-Cardo C: Expression of $\mathrm{c}$-kit and kit ligand proteins in normal human tissues. J Histochem Cytochem 1994, 42:1417-1425.

19. Demetri GD, Wang $Y$, Wehrle $E$, Racine A, Nikolova Z, Blanke CD, Joensuu $H$ von Mehren M: Imatinib plasma levels are correlated with clinical benefit in patients with unresectable/metastatic gastrointestinal stromal tumors. J Clin Oncol 2009, 27:3141-3147.

\section{Pre-publication history}

The pre-publication history for this paper can be accessed here: http://www.biomedcentral.com/1471-2407/10/438/prepub

doi:10.1186/1471-2407-10-438

Cite this article as: Hwang et al:: Imatinib induced severe skin reactions and neutropenia in a patient with gastrointestinal stromal tumor. BMC Cancer 2010 10:438.

\section{Submit your next manuscript to BioMed Central} and take full advantage of:

- Convenient online submission

- Thorough peer review

- No space constraints or color figure charges

- Immediate publication on acceptance

- Inclusion in PubMed, CAS, Scopus and Google Scholar

- Research which is freely available for redistribution

Submit your manuscript at www.biomedcentral.com/submit 